\title{
DESIGN AND ANALYSIS OF COMB SHAPE MICROSTRIP PATCH ARRAY ANTENNA FOR WLAN APPLICATIONS
}

\author{
B. Ramya, C. Supratha and S. Robinson \\ Department of Electronics and Communication Engineering, Mount Zion College of Engineering and Technology, India
}

\begin{abstract}
A comb shape rectangular slotted $1 \times 4$ microstrip patch array antenna is proposed and designed for wireless local area network applications. The functional parameters of the antenna namely, return loss, VSWR, radiation pattern are analyzed. The FR4 substrate is used to the proposed antenna. The dimension of proposed antenna is $143 \mathrm{~mm}$ of width and $71 \mathrm{~mm}$ of length and the patch dimension is $29.6 \mathrm{~mm}$ of width and $38 \mathrm{~mm}$ of length. The return loss and VSWR of $1 \times 4$ array antenna is $-34.8815 d B$ and 1.012, respectively. The rectangular slots are taken in equal length and width in order to enhance the performance.
\end{abstract}

Keywords:

Microstrip Patch Array, WLAN, Rectangular Slot, FR4, 1 × 4 Array, Return Loss

\section{INTRODUCTION}

In recent years, the development of telecommunication system has given to a variety of services including wireless local area network (WLAN) [1], long term evolution (LTE) [2] and laptops or cell phones. Antennas are mostly used for wireless communication. The most available antennas like microstrip patch antenna [3], monopole antenna [4], dipole antenna [5], array antenna [6], loop antenna [7] and aperture antenna [8]. Even then microstrip patch antenna guarantees low profile, compact and affordable manufacturing for real time applications. An antenna is an electrical conductor. It can be used for both transmission and reception and also a transducer. An antenna array is a set of individual antennas used for transmitting or receiving radio waves. Array antenna is mainly used for improving performance of communication systems and used to reduce the interference that are coming from different directions [9]. It provide higher gain and directivity.

WLAN is a wireless computer network that connects two or more users through wireless method within a limited area such as a home, school, computer laboratory, or office building. Most modern WLANs are based on IEEE 802.11 standards and are marketed under the Wi-Fi brand name [10]. The IEEE 802.11 has two basic modes of operation: infrastructure and ad hoc mode. In adhoc mode, mobile units transmit directly peer-to-peer. In infrastructure mode, mobile units communicate through an access point that serves as a bridge to other networks

In the literature, there are multitudinous techniques is employed to design the microstrip patch array antenna for WLAN applications, such as, Yagi array antenna [12], log-periodic array antenna [13], dipole array antenna [14], high gain double-sided array antenna [15] and multiband array antenna for WLAN/WiMAX [16]. From this reported work, it is scrutinized that the performance of the antennas is poor. To overcome these alleviate aforesaid issues, in this endeavor a rectangular slot is taken in these proposed microstrip patch array antenna [17]. Recently dual band multiport MIMO slot antenna [18], fourelement MIMO antenna [19], square ground plane with circularly etching and two arc-shape slotted stubs base antenna [20], wideband Fabry-Pérot resonator antenna [21], a bowtie-shaped MIMO dielectric resonator antenna [22] and hexagonal slot dual band frequency reconfigurable antenna [23] are reported for WLAN applications.

In this paper, a comb shape rectangular slotted microstrip patch $1 \times 4$ array antenna is proposed and designed for WLAN application. The resonant frequency of proposed antenna is 2.4GHz. This antenna is designed in FR4 substrate with $0.8 \mathrm{~mm}$ thickness, $1 \mathrm{~mm}$ feed width and substrate dimension of proposed antenna is $143 \mathrm{~mm}$ width and $71 \mathrm{~mm}$ length and patch dimension is $29.6 \mathrm{~mm}$ width and $38 \mathrm{~mm}$ length.

This paper is organized as follows. Section 2 describes the proposed antenna design. Section 3 presents results and discussion of proposed array antenna. The impact of return loss with respect to the frequency for substrate thickness and number of array elements are reported in section 4. Finally, section 5 presented the conclusions.

\section{ANTENNA DESIGN}

The proposed comb shape rectangular slotted $1 \times 4$ microstrip patch array antenna is shown in Fig.1. The formation of proposed patch antenna is design is depicted in Fig.2. The FR4 substrate is used with the dimension of $143 \mathrm{~mm}$ width and $71 \mathrm{~mm}$ length. The width and length of the patch are $29.6 \mathrm{~mm}$ and $38 \mathrm{~mm}$, respectively. The thickness of the substrate is $0.8 \mathrm{~mm}$ and a dielectric loss tangent is considered as 0.02 .

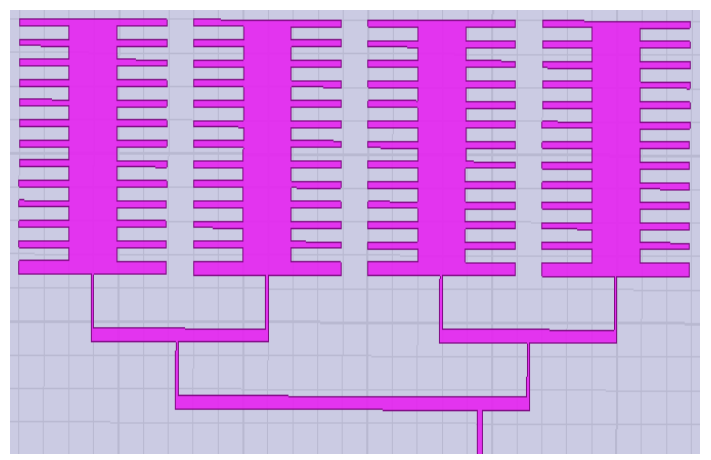

Fig.1. Schematic represenation of proposed $1 \times 4$ comb shape rectangular slotted microstrip patch array antenna

The microstrip feed with $1 \mathrm{~mm}$ feed width is employed. The proposed antenna structure is designed like a comb; all the rectangles are similar in dimensions except the last rectangle. There are 13 slots positioned in each dimension. The structural 
parameters of comb Shape rectangular slotted $1 \times 4$ microstrip patch array antenna are listed in Table.1. The proposed antenna is designed using High Frequency Structural Simulator (HFSS) software. In microstrip patch antenna, the width and length are most vital parameters which are ascertained using [24].

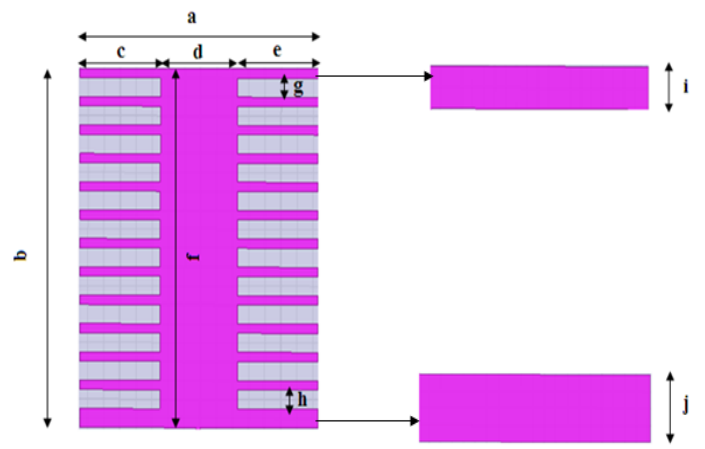

Fig.2. Sectional view of patch formation of the proposed antenna

Table.1. Structural details of comb shape rectangular slotted $1 \times 4$ microstrip patch array antenna

\begin{tabular}{|c|c|}
\hline Parameter & Values (mm) \\
\hline$a$ & 29.6 \\
\hline$b$ & 38 \\
\hline$c$ & 10 \\
\hline$d$ & 9.6 \\
\hline$e$ & 10 \\
\hline$f$ & 38 \\
\hline$g$ & 2 \\
\hline$h$ & 2 \\
\hline$i$ & 1 \\
\hline$j$ & 2 \\
\hline
\end{tabular}

\section{SIMULATION RESULTS AND DISCUSSION}

The Fig. 3 shows that the return loss of comb shape rectangular slotted $1 \times 4$ Microstrip patch array antenna. The return loss of proposed antenna is $-34.8815 \mathrm{~dB}$ at resonant frequency of $2.4 \mathrm{GHz}$.

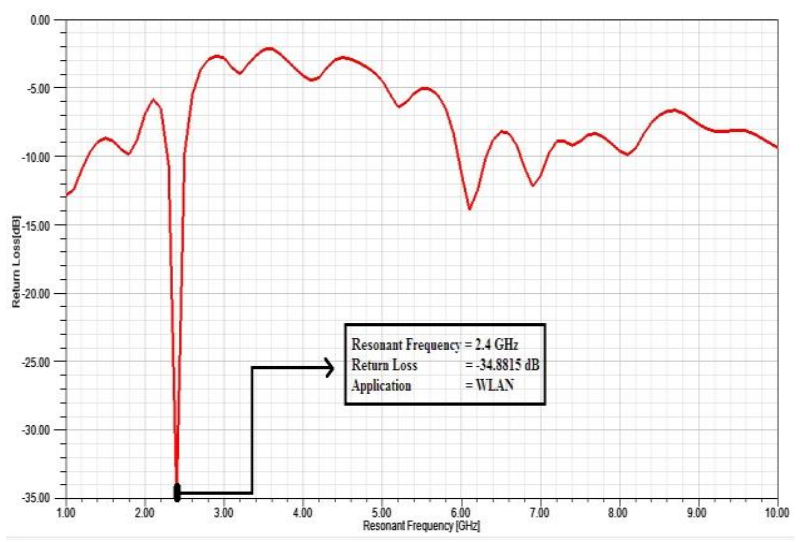

Fig.3. Return loss of the proposed proposed $1 \times 4$ comb shape rectangular slotted microstrip patch array antenna

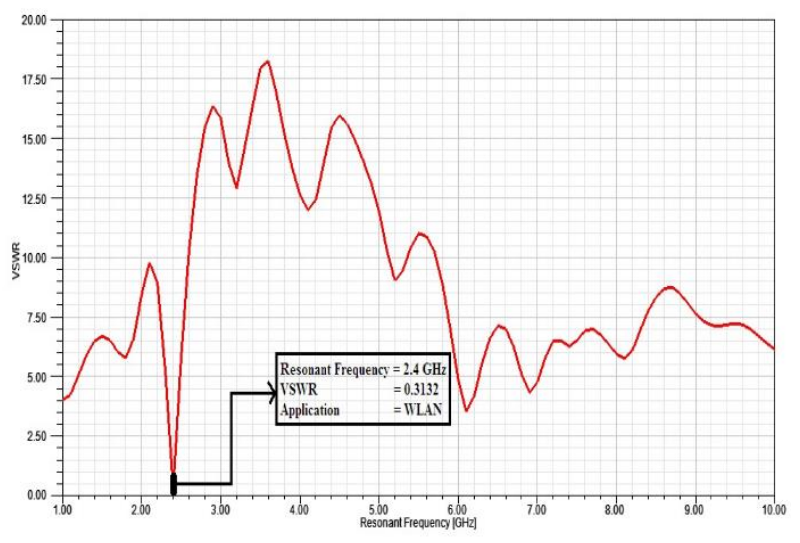

Fig.4. VSWR of the proposed antenna

The Fig.4 depicts the response of the VSWR for proposed comb shape rectangular slotted $1 \times 4$ microstrip patch array antenna. The VSWR of proposed antenna is 1.012 at $2.4 \mathrm{GHz}$. The value of the return loss and VSWR is altered or controlled by increasing the number of slots in the comb drive. The simulated radiation pattern of proposed antenna is shown in Fig.5. The representation of the $2 \mathrm{D}$ radiation pattern of simulated result is isotropic radiation pattern. The proposed antenna meets the requirements of WLAN application.

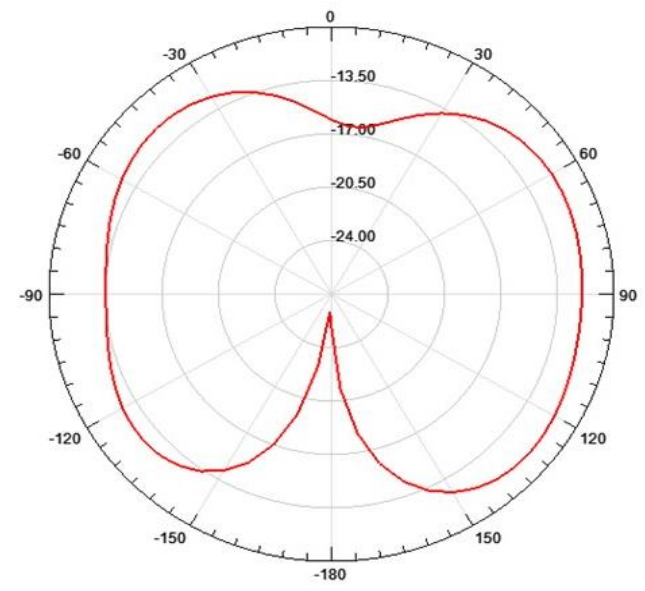

Fig.5. Radiation pattern of proposed antenna

Antenna gain is measured by antenna's ability to direct or concentrate radio frequency energy in a required direction or pattern. The gain of the antenna is $12.85 \mathrm{~dB}$. Directivity is a measure of performance of an antenna. Directivity is defined as the relation of the maximum radiation intensity to the average radiation intensity. The directivity of the proposed antenna is $13.18 \mathrm{~dB}$.

\section{PARAMETRIC ANALYSIS}

Here, initially the effect on return loss while increasing the substrate thickness is analyzed. Then the return loss of the antenna is investigated by varying the antenna elements from 1 to 8 in the design. The Fig. 6 shows the impact of return loss while varying the substrate thickness. It is observed that the return loss is about $-35 \mathrm{~dB}$ at $0.8 \mathrm{~mm}$ of substrate thickness. However, the performance is diminished for the substrate thickness of $1.6 \mathrm{~mm}$ and $3.2 \mathrm{~mm}$. 
Here substrate thickness of $0.8 \mathrm{~mm}$ is used as it produced the better return loss when compared with the substrate thickness of $1.6 \mathrm{~mm}$ and $3.2 \mathrm{~mm}$.

The Fig.7 shows the comparison analysis of comb shape rectangular slotted microstrip patch array antenna. From the simulated results, it is clearly investigated that there is resonant frequency shift while varying the number of array elements in an antenna. Further, there is significant improvement of return loss is observed at $1 \times 4$ array antenna.

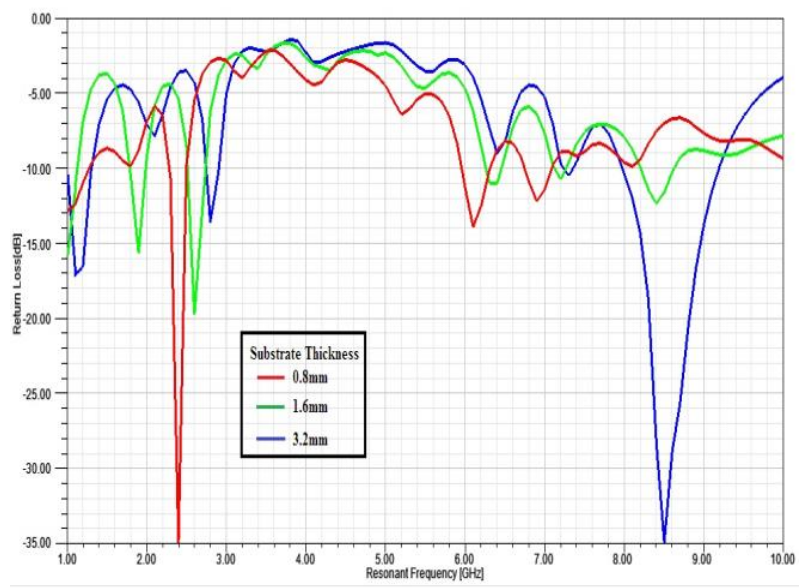

Fig.6. Impact of return loss with respect to substrate thickness

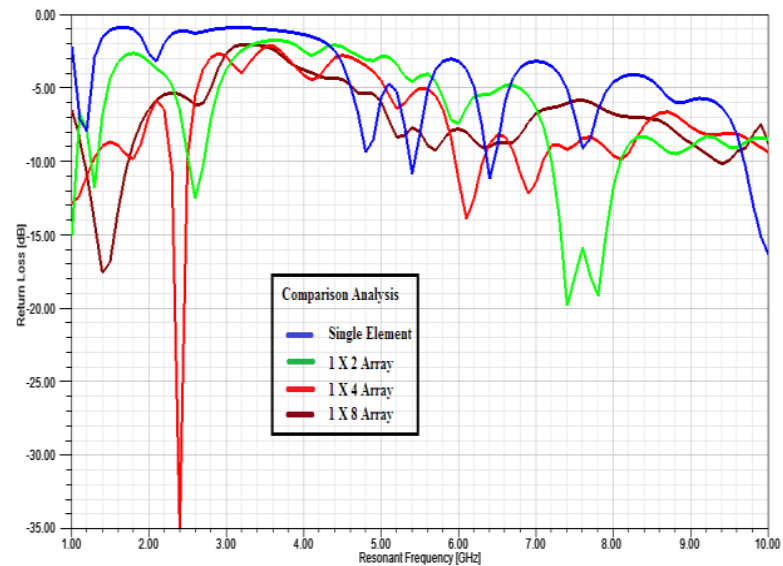

Fig.7. Comparison analysis of return loss vs. frequency of a single element patch, array of $1 \times 2,1 \times 4$ and $1 \times 8$ comb shape rectangular slotted microstrip patch array antenna

\section{CONCLUSION}

In this attempt, a comb shape rectangular slotted $1 \times 4$ microstrip patch array antenna is proposed and designed for WLAN application. The functional characteristics of the proposed array antenna investigated namely return loss, VSWR, gain and directivity. The proposed $1 \times 4$ array antenna is resonating at $2.4 \mathrm{GHz}$, and the return loss and VSWR is about, $-34.8815 \mathrm{~dB}$ and 1.012 , respectively. The overall size of the proposed array antenna is $143 \mathrm{~mm} \times 71 \mathrm{~mm}$ and the patch dimension is $29.6 \mathrm{~mm}$ width and $38 \mathrm{~mm}$ length. Hence it could be amalgamated for WLAN applications.

\section{REFERENCES}

[1] Deepti Saxena, Sweta Agarwal and Sumit Srivastava, "Low Cost E-Shaped Microstrip Patch Antenna Array for WLAN", International Journal for Advanced Research in Electrical, Electronics, Instrumentations Engineering, Vol. 3, No. 4, pp. 8831-8838, 2014.

[2] Sven Erik Sandstrom, "A Compact Microstrip Patch Antenna for LTE Applications", Master Thesis, School of Computer Science, Physics and Mathematics, Linnaeus University, 2013.

[3] Y.T. Lo, D. Solomon and W.F. Richards, "Theory and Experiment on Microstrip Antenna", IEEE Transaction on Antennas and Propagation, Vol. 27, No. 2, pp. 137-149, 1979.

[4] Melvin M. Weiner, "Monopole Antennas", CRC Press, 2003.

[5] Yuh-Yih Lu, Jhih-Jie Jhu and Hsiang-Cheh Huang, "Design of High Gain Planar Dipole Array Antenna for WLAN Application", Proceedings of IEEE $9^{\text {th }}$ International Conference on Intelligent Information Hiding and Multimedia Signal Processing, pp. 1-4, 2013.

[6] Peter Bevelacqua, "Array Antennas", Available at: www.antenna-theory.com, Accessed on 2017.

[7] Magnetic Loop Antennas Receiving, Available at: http://www.w8ji.com/magnetic-receiving-loops.htm

[8] K.D. Prasad, "Antennas and Wave Propagation", Satya Prakashan, 2009.

[9] Constantine A. Balanis, "Antenna Theory: Analysis and Design", Wiley, 2005.

[10] P. Jothilakshmi, R. Narasimman, B. Praveen and R.K. Vigneswaran, "Design of and Development Quad-Band H Shaped Microstrip Patch Antenna for WiFi and LTE Application", WSEAS Transactions on Communications, Vol. 13, pp. 234-241, 2014.

[11] Jaume Anguera, Aurora Andujar, Minh-Chau Huynh, Charlie Orlenius, Cristina Picher and Carles Puente, "Advances in Antenna Technology for Wireless Handheld Devices", International Journal of Antennas and Propagation, Vol. 2012, pp. 1-25, 2012.

[12] Yun Hao, Haomeng Tong and Xihong Ye, "Circularly Polarized Microstrip Yagi Array Antenna with Wide Beamwidth and High Front-to-Back Ratio", International Journal of Antennas and Propagation, Vol. 2016, pp. 1-15, 2016.

[13] Giovanni Andrea Casula and Paolo Maxia, "A Multiband Printed Log-Periodic Dipole Array for Wireless Communications", International Journal of Antennas and Propagation, Vol. 2014, pp. 1-6, 2014.

[14] Changhong Zhang, Xianling Liang, Junping Geng and Ronghong Jin, "Broadband Dual Circularly Polarized Magneto Electric Dipole Antenna Fed by a Miniaturized Six-Branch Hybrid Coupler", International Journal of Antennas and Propagation, Vol. 2016, pp. 1-10, 2016.

[15] I. Islam, M.F. Jamlos and N.A. Rahman, "A High Gain Double-Sided Array Antenna for LTE and WLAN Applications", Proceedings of IEEE International RF and Microwave Conference, pp. 136-140, 2015.

[16] Yun-Hong He and Jiu-Sheng Li, "A Novel Multi-band Array Antenna for WLAN/WiMAX Applications", 
Proceedings of IEEE $4^{\text {th }}$ International Symposium on Microwave, Antenna, Propagation and EMC Technologies for Wireless Communications, pp. 246-248, 2011.

[17] Ashutosh Kumar Singh, Stuti Sriva Stave, Vinod Kumar Sing and Zakir Ali, "Duo Triangular shaped Microstrip Patch Antenna Analysis for WiMAX Lower Band Application", Procedia Technology, Vol. 10, pp. 554-563, 2013.

[18] Saber Soltani, Parisa Lotfi and Ross D. Murch, "A DualBand Multiport MIMO Slot Antenna for WLAN Applications", IEEE Antennas and Wireless Propagation Letters, Vol. 16, pp. 529-532, 2017.

[19] Soumen Pandit, Akhilesh Mohan and Priyadip Ray, "A Compact Four-Element MIMO Antenna for WLAN Applications", Microwave and Optical Technology Letters, Vol. 60, No. 2, pp. 289-295, 2018.

[20] M. Ghahremani, Ch. Ghobadi, J. Nourinia, M. Karamirad and B. Mohammadi, "A Novel Circularly Polarized Modified Slot MIMO Antenna for WLAN Applications", Microwave and Optical Technology Letters, Vol.59, No.4, pp. 876-880, 2017.
[21] Mohamed Lamine Abdelghani, Hussein Attia and Tayeb Ahmed Denidni, "Dual-and Wideband Fabry-Perot Resonator Antenna for WLAN Applications", IEEE Antennas and Wireless Propagation Letters, Vol. 16, pp. 473-476, 2016.

[22] Muhammad Amin, Ting Ting Bu, Chao-Ming Luo, Muhammad Abdul Basit and Jing-Song Hong, "A Bowtieshaped MIMO Dielectric Resonator Antenna for WLAN Applications", IEICE Electronics Express, Vol. 14, No. 12, pp. 519-523, 2017.

[23] Tanweer Ali and Rajashekhar C. Biradar, "A Compact Hexagonal Slot Dual Band Frequency Reconfigurable Antenna for WLAN Applications", Microwave and Optical Technology Letters, Vol. 59, No. 4, pp. 958-964, 2017.

[24] Shantwng He and Jidong Xie, "Analysis and Novel Design of a Novel Dual Band Array Antenna with a Low Profile for 2400/5800 MHz WLAN Systems", IEEE Transactions on Antennas and Propagation, Vol. 58, No. 2, pp. 391-396, 2010. 